\title{
Resistance Through Form: Masonry Synthesis Structures in the Design of a New Residential Architecture for Khartoum, Sudan
}

\author{
MOHAMED ISMAIL \\ University of Virginia
}

With one of the highest urbanization rates in Africa, at $4.3 \%$, per anum, nearly half of Sudan lives in its cities. Two-thirds of that urban population lives in slums or otherwise informal settlements, and current construction practices and housing policies cannot meet growing housing needs.

There is an opportunity for architecture that responds to the housing needs and material availability while reflecting local housing traditions. Synthesis structures are structures informed by their material understanding, their process of construction, and inform their interior space and texture (Corrao and Pastre). This includes traditional compressive forms like the arch, vault, and dome, and more. The raw materials and the labor needed for masonry are plentiful in Sudan, especially in Khartoum at the clay-rich riverbeds of the Niles (Alam).Unfortunately, earthen construction suffers the stigmas of poverty, structural insufficiency, and deficient technical knowledge (Osmani and Hadjri). Masonry synthesis structures may potentially overcome the perceived cultural and performative limitations of earthen construction. Worldwide, there are ongoing efforts to reimagine the possibilities of earth-based construction in cities. This is not a new phenomenon; in Architecture for the Poor, Hassan Fathy explored the use of mudbrick beginning in the 1930 s (Fathy). Fathy referenced traditional and vernacular architecture to inform the contemporary design of rural housing. Today, architects are learning from centuries of vernacular architecture while pushing traditional material use further than ever before. This research identifies potential new applications of masonry synthesis structures in the design of a new urban residential architecture in Khartoum, Sudan.

\section{BACKGROUND}

Worldwide, there are ongoing efforts to reimagine the possibilities of earth-based construction in cities. This is not a new phenomenon; in Architecture for the Poor, Hassan Fathy explored the use of mudbrick beginning in the 1930s (Fathy). Fathy referenced traditional and vernacular architecture to inform the contemporary design of rural housing. Today, architects like Wang Shu and Francis Kere, and institutions like the Earth Institute of India and CRAterre of France, are learning from centuries of vernacular architecture while pushing traditional material use further than ever before. Soil is the most widely used building material in developing countries, between one-third and one-half of the world lives in earthen buildings (Rael). It is cheap, widely accessible, cost-effective and climatically comfortable when used responsibly. Yet there is an increase in urban development that abandons the use of local materials in favor of an international modern reliant on imported materials (Zami and Lee). With the proliferation of global trade, materials are no longer a limiting factor for construction in More Economically Developed Countries (MEDCs). This is not the case in Less Economically Developed Countries (LEDCs), where the use of imported materials significantly adds to the cost of construction, comprising between 50 and $80 \%$ of its total cost (Nwoke and Ugwuishiwu). The high costs of the international modern are largely due to lacking competition from locallyproduced materials, insufficient production, low quality, and high manufacturing costs. Thus, this research asks how local materials can inspire a new form of urban architecture in LEDCs,- beginning with Khartoum, the capital of Sudan.

\section{CONTEXT}

Formed at the meeting of the Blue and White Nile, the metropolitan area of Khartoum grew from 750,000 in the 1970 s to 6.5 million people today (Eltayeb). Since its independence from British rule in 1956, Sudan has endured decades of instability with two civil wars between the north and south, a war in Darfur, and the secession of South Sudan in 2011. With one of the highest urbanization rates in Africa, at 4.3\%, per annum, nearly half of the country lives in its cities. Two-thirds of that urban population lives in slums or otherwise informal settlements, and the construction industry and housing policies do not meet their needs.

It was estimated that the demand for urban housing in Sudan was more than 540,000 units in 1985 , rising to over 920,000 by 2012 . Over $60 \%$ of that need is in the Greater Khartoum area alone. By 2020, this need is expected to reach 2,000,000 units (Pantuliano, Assal and Elnaiem). Khartoum has experienced rapid horizontal sprawl due to various circumstances: the abundance of flat land, the cheap cost of local building materials, the government policy of land allocation to each acceptable family head, and an assortment of environmental and social-cultural conditions (e.g. sleeping in the open air due to hot weather, separation of spaces by gender, extended families and the high frequency of guests). About $90 \%$ of residential buildings only consist of a ground floor, and $73 \%$ are made of brick and mud. Additionally, 93\% of the population of Khartoum live in homes made through individual labor, and $43 \%$ of these are shacks of non-durable materials (Eltayeb). 


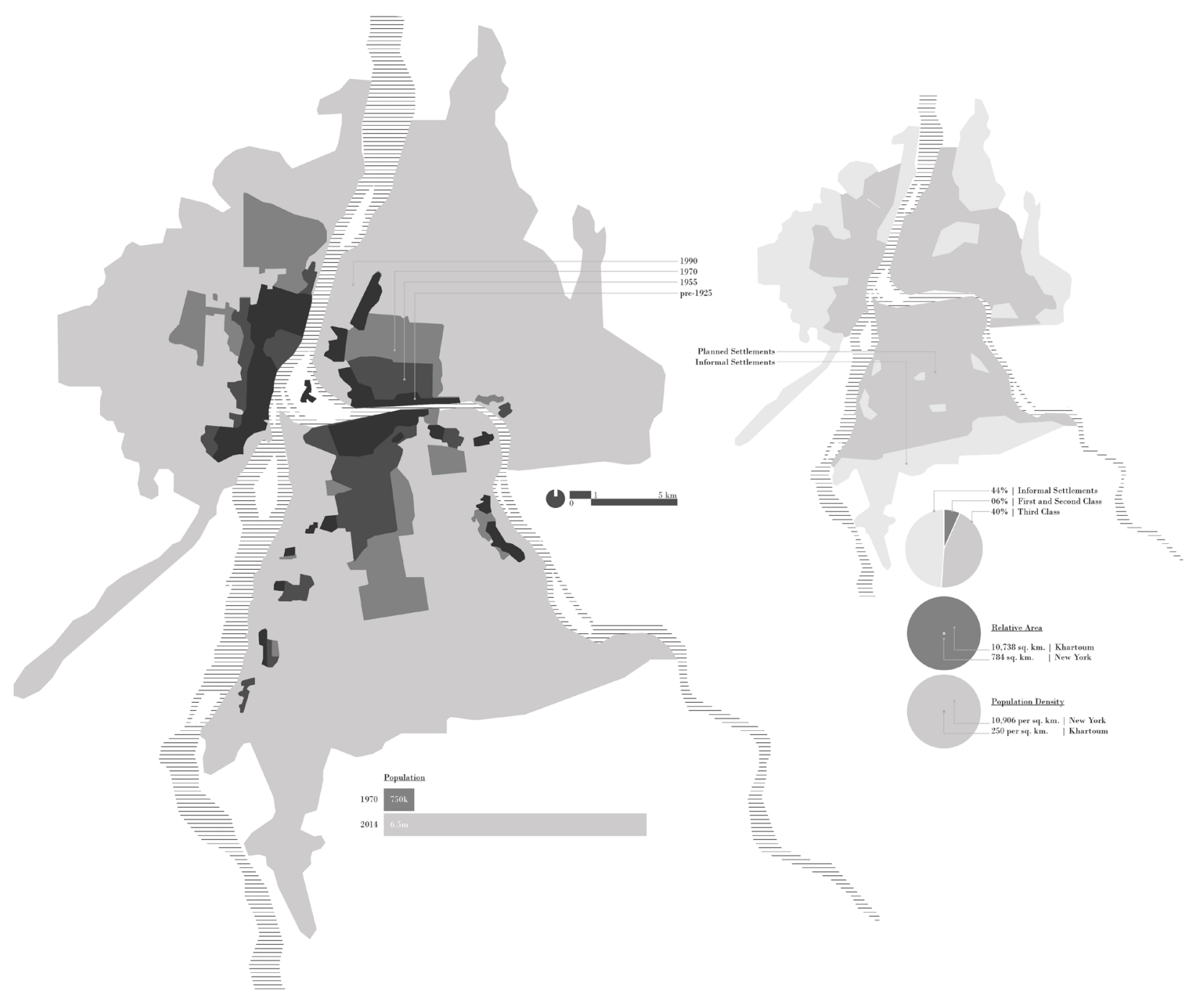

Figure 1: Khartoum has experienced rapid population growth and horizontal expansion over the past few decades.

The residential zones of Khartoum can be divided into three categories: first and second class ( $6 \%$ of total residential area), third class (40\%) and squatter settlements (54\%). The high cost of land ownership, construction, and housing policies affect each residential class differently. Despite the high percentage of plots sold in first and second class neighborhoods, the plots developed rarely exceed $20 \%$. Due to the inability to build "appropriate" permanent homes and pay for their plots during resettlement periods, more than half of the urban poor in Khartoum have been forced to relocate between one to three times since moving to Khartoum (El-bushra and Hijazi).

\section{RESEARCH QUESTIONS}

There is an opportunity for architecture that responds to the housing needs and material availability while reflecting local housing traditions. The potential impact of an architecture that consists of local materials is clear: construction materials alone make up 58-60\% of building costs in Sudan (Elkhalifa and Shaddad). Speculatively, synthesis structures are structures informed by their material understanding, process of construction, and inform their interior space and texture (Corrao and Pastre). Masonry synthesis structures may potentially overcome the perceived cultural and performative limitations of earthen construction. This paper explores the latent possibilities of masonry synthesis structures in the design of a new urban residential architecture in Khartoum, Sudan.

To begin with, the following research questions must be addressed:

- What defines the Sudanese home? What construction practices developed because of this definition?

- Can synthesis structures stimulate interest in the construction of earthen homes at varied socioeconomic levels?

- Is the application of form-finding techniques and freeform masonry structures informed by an economy of means practical in a context like Khartoum, Sudan? 


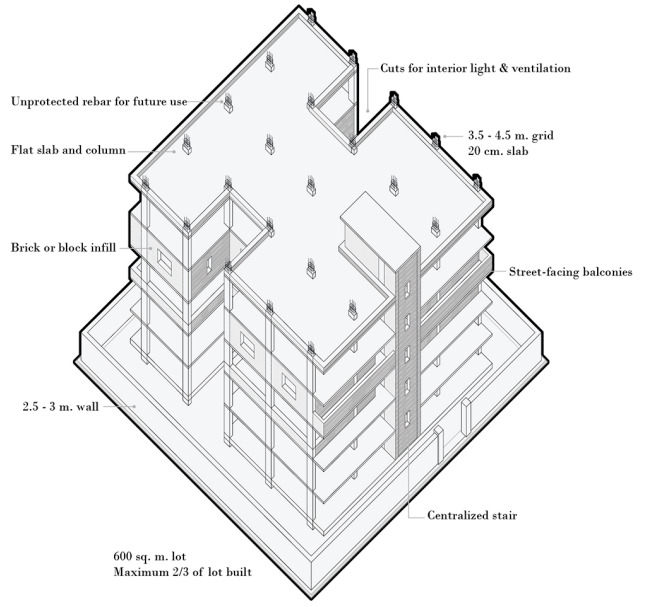

First Class Condominium | $\$ 500$ - 600 per sq. m.
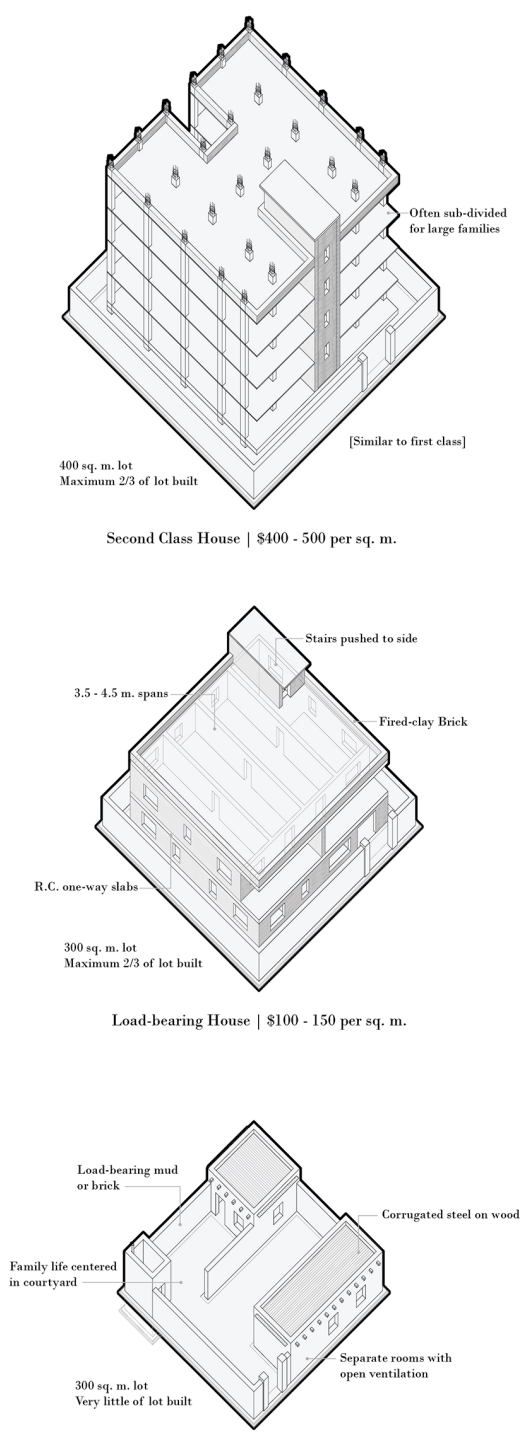

Courtyard House | $\$ 80$ - 100 per sq. m.

Figure 2: Common housing typologies and their corresponding construction practices in Khartoum.
Sudan has no identifiable urban vernacular architecture suited to its material and immaterial context. For those that can afford it, construction materials are imported from abroad for buildings that mimic a "western" architecture of glass, concrete, and steel buildings ill-equipped for the harsh climate and lack of skilled labor. For those that cannot, informal and semi-permanent buildings are made from cheap material and insufficient construction techniques leaving the buildings vulnerable to natural disasters and the ravages of time.

The "idealized" house asks for materials that have no industry in the Sudan; $85 \%$ of cement and finishing materials are imported and steel for construction accounts for $5-8 \%$ of the Sudan's total import expenditure (Elkhalifa and Shaddad). However, raw materials and the labor needed for sunbaked and fired clay masonry are plentiful in Sudan, especially in Khartoum at the clay-rich river beds of the two Niles. Between 1994 and 2000 the number of brick-laying companies rose from 650 to 2,000 , accounting for $88.5 \%$ of Sudan's national brick production (Alam). Unfortunately, earthen construction suffers the stigmas of poverty, structural insufficiency, and deficient technical knowledge (Osmani and Hadjri).

\section{RESEARCH OUTLINE}

This proposal is a retooling of long-existing building practices with universal materials and burgeoning technologies in a context familiar to the researcher, intentionally limiting the scope while engaging in the larger dialogues of compressive structures and housing insecurity in sub-Saharan nations. There is precedence in Heinz Isler's elegant concrete shells, Felix Candela's economic doubly-ruled surfaces, Rafael Guastavino's versatile thin-tile vaults, and Eladio Dieste's graceful brick vaults. In the end, this research explores the connections between structural analysis and architectural design in a context that is poorly understood.

Research is lacking in the potential application of advanced form-finding technologies and material optimization to the widespread issues of housing insecurity. And, although there is a significant body of work dedicated to housing insecurity in Khartoum and policy suggestions, it often overlooks the fact that most homes in Sudan are built through individual labor. Ultimately, this proposal seeks a solution to Khartoum's housing crisis by starting with the solitary masonry unit. Rather than investigating the benefits of widespread policy reform, this research looks at the assemblage of an earthen home and asks how it can better serve populations like that of Khartoum. This involves an exploration of climactic comfort, structural capacity, housing traditions, and more.

The first phase of research was a literature review focusing on advances made in form-finding technology with compressive materials, contemporary approaches to critical regionalism, case studies in similar regions, and the viability of local 


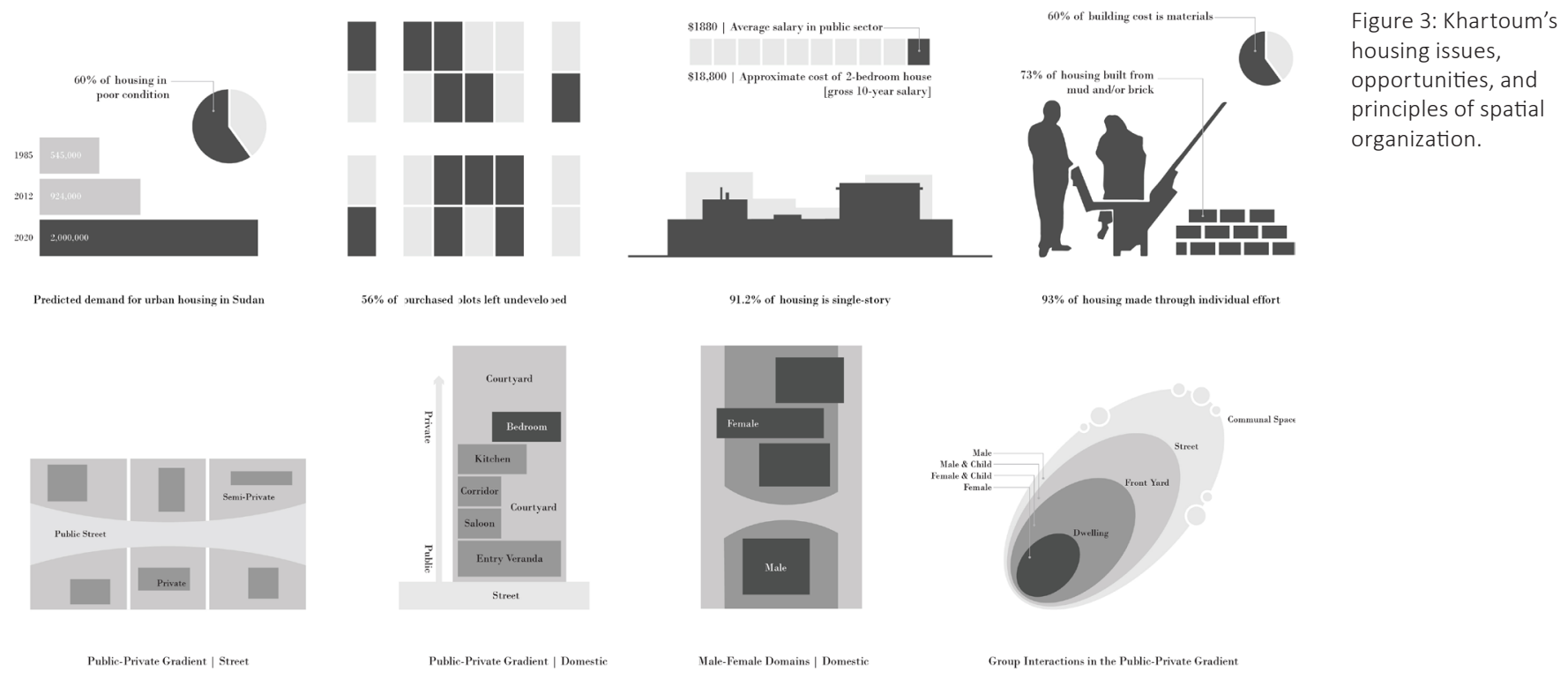

materials compared to imported materials. This drew from the work of the Auroville Earth Institute in India, the Block Research Group in Switzerland, the Nubian Vault Association (AVN), and CRAterre in France while searching for potential applications of their findings in Khartoum. The second phase involved experimentation with digital optimization tools, form-finding techniques, and physical testing as a proof-ofconcept at multiple scales. The onus of this research was that of performance and space-making as a holistic practice in experimentation and contextualization. The final stage of this research was the development of a framework for the practical implementation of these findings.

\section{LITERATURE FINDINGS}

When consulting internationally recognized measures of adequate housing conditions (guaranteed tenure, number of rooms, people per unit, quality of latrines, kitchens, secure fencing, etc.), Khartoum falls short. With $60 \%$ of existing housing in poor condition there is a deficit of more than 1.2 million housing units in the city (equivalent to $22 \%$ of housing requirements). In addition, the majority of buildings are built without permit; it is reported that only 4,500 building permits are issued a year, against an annual demand of 60,000 units (Pantuliano, Assal and Elnaiem). The majority of Khartoum's urban poor live in informally built homes, resulting in a propagation of mostly illegal poor housing, dependent upon varying degrees of self-help by the inhabitants.

To understand the sociocultural dimension of housing design and construction in Khartoum, several case studies were studied. This resulted in an examination of homes from various socioeconomic groups extracted from the 1995 study, Khartoum: A Profile of Urban Housing, by the ETH Zurich Habitat Group led by Professor H. E. Kramel (Kramel). This study helped distinguish a set of housing typologies most commonly built in Khartoum and revealed the impact of a person's socioeconomic condition on their house's construction and material composition. This analysis also resulted in a series of diagrams displaying a spatial organization that reflected the zones of interaction, separation of genders, familial living, and gradient of privacy that defined a typical Sudani home. These diagrams became the framework for following design explorations.

\section{DESIGN PROBLEM}

With the rising cost of land and construction, homes have become smaller and denser in composition. As a result, the Sudani family suffers. Gatherings have seemingly always been a part of Sudani culture; gatherings for weddings, funerals, the birth of a child, the return of a loved one, and more. The dwelling has largely been the initial space of familial and neighborly gathering. As the dwelling decreased in size, the space for gathering was pushed out and away. It moved from the courtyard, to the street, to the event hall across town. This proposal sought to resolve the issues facing the Sudani family in a rapidly expanding urban context. Multi-family housing with shared public spaces could potentially abet the housing insecurity of Khartoum while remaining cognizant of the social definition of the Sudani home.

\section{TOOLS AND METHODS}

Beyond the spatial organization of Sudani housing, the proposal needed to reflect the material opportunities in Khartoum's construction sector. Site visits were made to construction sites and production facilities with local engineers throughout Khartoum in order to survey common practices and material options. Consequently, it was determined that the most utilized materials in construction were reinforced concrete - albeit with limited oversight and quality control - fired clay brick, and stabilized soil block (SSB). This proposal made use of the later. In recent years, work had been done by UNESCO and UN-Habitat to make a case 

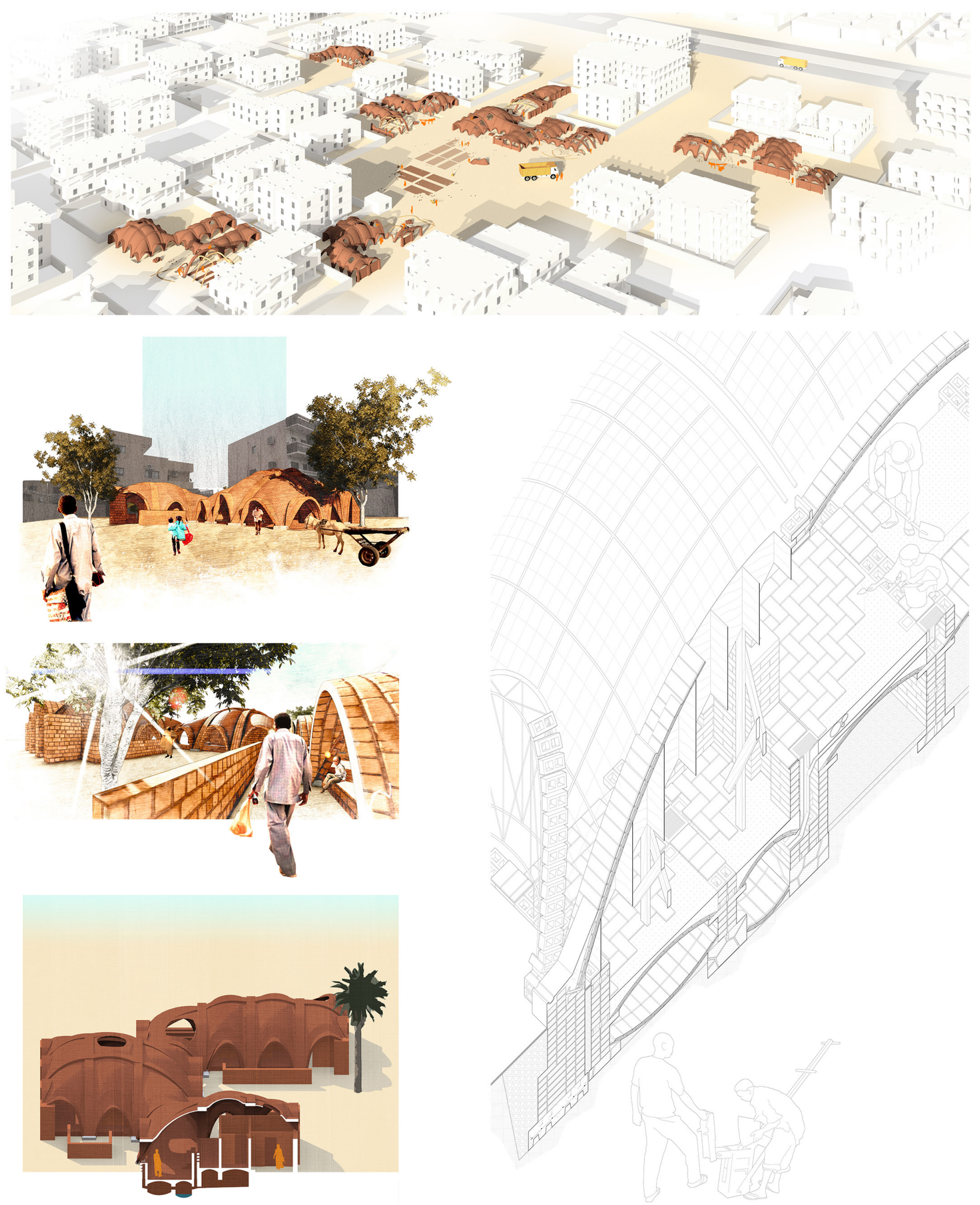

Figure 4: Design proposal. Clockwise from above: aerial material preparation and construction process, detail construction section, interior section, courtyard view, street view 
for the proliferation of SSB technology over other materials in Sudan. Summarized, their reports determined that SSB had a significantly lower embodied energy, economic cost, better compressive strength, better water resistance, and needed less water than fired clay brick and reinforced concrete. In addition, the materials needed were abundantly available - a large part of Khartoum was covered in black cotton soil - and low odds for seismic activity made compressive structures strong prospects for housing. However, only one building of note was built to showcase the possibilities of SSB: El Haj Yousef School in North Khartoum.

Outside of Sudan, efforts have been made by organizations including the Block Research Group and the Earth Institute to reintroduce age-old earthen materials into a catalogue of contemporary structural technologies. This work has resulted in new tools like RhinoVault, developed by Matthias Rippmann and Philippe Block, to provide designers with a way to use Thrust Network Analysis - a form of three-dimensional Graphic Statics - in an intuitive process of compressive formfinding and exploration (Rippman, Lachlauer and Block). These developments have renewed interest in compressive structures and their new-found design possibilities in regions where other materials are deemed impractical. Notable examples include the Sustainable Urban Dwelling Unit in Ethiopia (Block, DeJong and Davis), and the Mapungubwe Interpretive Center in South Africa (Ramage, Ochsendorf and Rich) where tiles made primarily from local soils were used to construct structurally efficient shell structures for roof and floor systems reminiscent of Rafael Guastavino's structures of the late 19th century.

\section{DESIGN PROPOSAL}

Finally, a design was proposed that combined an interpretation of the Sudani home, an appreciation of the material limitations of construction in Khartoum, and an opportunity to make use of burgeoning tools in structural optimization and analysis. The result was a system of single-story multifamily houses consisting of shared courtyards and corridors, increasing the density of Khartoum without necessitating - nor precluding - vertical expansion. The system was defined by thin tile shells supported by hollow-block arching ribs, reducing the amount of material needed for falsework and allowing for variability in the roofing forms based on a family's immediate and future needs. Using readily available materials such as plywood profiles for ribs, bent rebar trusses for edge profiles, and slab reinforcement for the thintile shells, falsework was simple and repetitive - potentially reused or becoming permanent fixtures once construction was complete. The construction process suggests a possibility of expansion over time and variation in its material make-up dependent upon the financial capacity of the family. For instance, three structural foundation options (stone, masonry, and concrete floating-slab) were proposed that relate capital cost of construction to their need for future maintenance. Climactically, there was an opportunity to study past solutions as Hassan Fathy once had;, reintroducing the wind-catcher, for example, to cool interior spaces and collect rainwater from the sloping roofs. The proposal advocated that families would define living spaces according to their personal beliefs; shifting mindsets and changing traditions could define internal organizations accordingly. This was not imagined as a one-time erection, but an ongoing enterprise that provided the Sudanese agency over their homes and their creation - from excavation, to material preparation, to expansion and modification over a lifetime.

\section{BEYOND THE DESIGN}

The design proposal shown above is one example of how designers can make use of synthesis structures in the alleviation of housing insecurity. Through the use of burgeoning technologies in structural and material optimization, lowtechnology construction techniques, and an understanding of local material availability and behavior, the potential uses of soil - a material already widely available and in use worldwide - are expanded manifold. This does not mean that earthen-construction will be accepted as an immediate alternative to the international modern, but it does become an increasingly viable option in the pursuit of economically and environmentally cost-effective construction. Nonetheless, the success of this approach would depend upon a variety of obstacles being overcome. For example, housing policy in Khartoum classifies soil as a material unfit for first and second class dwellings, reflecting the long-standing stigma towards earthen-construction. This limits technological research and innovation in low-cost soil construction, and must be addressed before wide-spread change can occur. Organizations such as the Auroville Earth Institute in India and the NKA Foundation in Ghana have set a precedent in overcoming this stigma through demonstration projects, inviting designers and engineers to rethink soil construction technologies and present them as an alternative to the oft-desired steel and concrete buildings of the international modern. This is a model that could be replicated worldwide, with the governments of LEDCs having the most influence through policy changes that reflect technological advancements, supplements to building codes, and building demonstrations that encourage responsible earthen building technologies as discussed above.

Additionally, the design proposal was a response to the default affordable housing program initiated worldwide by governments, aid groups, and development organizations. To deliver as many homes as possible as quickly as possible, the design solution often becomes a repetitive module of partially prefabricated elements that have little to no relationship with their context (e.g. prefabricated apartment blocks, stud-wall mobile homes, and collapsible plastic tents). The materials are foreign, the local labor is minimized, nothing beyond the building is gained (new skills, trades, and technologies), and 
the programming has little to no input from the community - the benefactors are removed from the process entirely. In response, this proposal began with a study of the sociocultural features of local housing - frequently neglected in affordable housing projects - and used the available materials and appropriate technologies as a catalyst for the final design. The ultimate goal was to develop a system of construction that provided agency to local families, construction workers, and manufacturers by keeping their needs and capabilities in mind. This is an approach that may potentially be adapted for any context, reminiscent of Hassan Fathy and similar designers' processes: beginning with what exists locally and going beyond the vernacular versus modern divide to design a system of construction that is relevant and contemporary.

\section{CONCLUDING THOUGHTS}

While the potential success of this system remains to be seen, this research provided an opportunity to explore structural and material optimization technology in a context that could benefit greatly from its application. Moreover, Khartoum is not an isolated case study in housing insecurity. According to UN-Habitat, 3 billion people - or $40 \%$ of the world's population -will need access to housing by 2030 (UN-Habitat). Furthermore, while material cost is not the only limitation to affordable housing construction, it remains a major component in LEDCs. This demands new approaches to housing that provide citizens with agency and ample opportunity to inform their built environment. With new tools of structural analysis and material optimization, designers have a capacity for performance-based design that not only engages the context but leaves room for improvement while concurrently improving the safety and comfort of their occupants. These tools are not new, nor are they unique. However, increasingly accessible formats allow for advanced collaborations between designers and consultants, and progressively informed design explorations by students and practitioners. The design proposal presented here is far from the only solution to global housing insecurity, and the anticipation is that analogous performance-based solutions are yet to emerge.

\section{ACKNOWLEDGEMENTS}

The author would like to express his sincere gratitude to his advisor and mentor, Jeana Ripple, assistant professor at the University of Virginia's School of Architecture, for her continued support and guidance throughout this research venture and beyond, and thank you to the faculty and staff at UVa for all of their support.

\section{ENDNOTES}

1 Alam, Syed Ashraful. 2006. "Use of biomass fuels in the brick-making industries of Sudan: Implications for deforestation and greenhouse gas emission."

2 Block, Philippe, Matthew DeJong, Lara Davis, and John Ochsendorf. 2010. "Tile vaulted systems for low-cost construction in Africa." ATDF Journal.

3 Corrao, R., and L. Pastre. 2010. "Filigree constructions vs solid constructions. The relationship between structure and architecture in the contemporary age." Structures and Architecture.

4 El-bushra, El-sayed, and Naila B. Hijazi. 1995. "Two Million Squatters in
Khartoum Urban Complex: The Dilemma of Sudan's National Capital." GeoJournal 505-514.

5 Elkhalifa, A., and M. Y. Shaddad. 2010. The Construction and Building Materials Industries in Sudan. Khartoum: University of Khartoum.

6 Eltayeb, Galal Eldin. 2003. The Case of Khartoum, Sudan. London: UN-HABITAT Case Studies.

7 Fathy, Hassan. 1973. Architecture for the Poor Gourna: An Experiment in Rural Egypt. Chicago: Chicago u.a.: Univ. Press.

8 Kramel, H. E. 1995. Khartoum: A Profile of Urban Housing. Zurich: Swiss Federal Institute of Technology.

$9 \quad$ Nwoke, O. A., and B. O. Ugwuishiwu. 2011. "Local Bamboo and Earth Construction Potentials for Provision of Affordable Structures in Nigeria." International Journal of Sustainable Construction Engineering and Technology 17-31.

10 Osmani, M., and Karim Hadjri. 2007. "Attitudes towards earth building for Zambian housing provision." Engineering Sustainability 141-149.

11 Pantuliano, Sara, Munzoul Assal, Butheina A. Elnaiem, Helen McElhinney, Manuel Schwab, Yathrib Elzein, and Hanaa Moutasim Mahmoud Ali. 2011. City Limits: Urbanization and Vulnerability in Sudan. Khartoum Case Study, London: Humanitarian Policy Group.

12 Rael, Ronald. 2009. Earth Architecture. Princeton Architectural Press.

13 Ramage, Michael, John Ochsendorf, Peter Rich, James Bellamy, and Philippe Block. 2010. "Design and Construction of the Mapungubwe National Park Interpretive Centre, South Africa." ATDF Journal.

14 Rippman, M, L Lachlauer, and P Block. 2012. "Interactive Vault Design." International Journal of Space Structures.

15 UN-Habitat. September 12, 2005. Financing Urban Shelter: The Housing Crisis Nairobi: UN-Habitat.

16 Zami, Mohammad Sharif, and Angela Lee. 2009. "Economic benefits of contemporary earth construction in low-cost urban housing - State-of-the-art review." Journal of Building Appraisal 259-271. 